\title{
SPK: Analisa Metode AHP Pada Guru Berprestasi di SD 095130 Senio Bangun
}

\author{
1) Friskila Parhusip \\ STIKOM Tunas Bangsa Pematang Siantar, Sumatera Utara, Indonesia \\ E-Mail:friskilaparhusip1406@gmail.com \\ 2) Asri Yustika \\ STIKOM Tunas Bangsa Pematang Siantar,Sumatera Utara,Indonesia \\ E-Mail:asriyustika@gmail.com \\ 3) Indah Syahputri \\ STIKOM Tunas Bangsa Pematang Siantar, Sumatera Utara,Indonesia \\ E-Mail:indahsyahputri@gmail.com \\ 4) Nila Soraya Damanik \\ STIKOM Tunas Bangsa Pematang Siantar,Sumatera Utara,Indonesia \\ E-Mail:nilasorayadamanik@gmail.com \\ 5) Solikhun \\ AMIK Tunas Bangsa Pematang Siantar,Sumatera Utara,Indonesia \\ E-Mail:solikhun@amiktunasbangsa.ac.id
}

\begin{abstract}
ABSTRAK
Sistem pendukung keputusan ini digunsakan untuk memilih guru berprestasi dan ditujukan untuk SD 095130 Senio Bangun yang masih menggunakan sistem manual dalam menilai calon-calon guru berprestasi. Sehingga sistem ini diharapkan dapat membantu pihak dinas dalam proses penilaian dan penentuan guru berprestasi di wilayah Kota Pematang Siantar secara cepat dan tepat. Metode yang digunakan dalam perangkingan pemilihan guru berprestasi pada sistem ini menggunakan metode AHP yaitu suatu metode yang Cara kerja dari metode ini hampir mirip dengan cara kerja otak , yaitu dengan cara menguraikan masalah kompleks menjadi masalah lebih yang lebih terstruktur dan sistematis.Dimana alternatif yang digunakan sebanyak 4 guru dengan kriteria jabatan, pendidikan, pangkat/gol/Ruang dan sk terakhir. Hasil dari perangkingan dalam sistem ini dipengaruhi oleh pemilihan kriteria preferensi dan penentuan yang dimasukkan ke dalam sistem. Pengujian sistem ini menggunakan data nilai dari 45 guru, yang perangkingannya dibagi menurut kelompok TK, SD/MI, SMP/Tsanawiyah, SMA/MA, dan SMK. Dari beberapa ujicoba yang telah dilakukan untuk menentukan guru berprestasi, hasil perangkingannya jauh lebih cepat dan lebih akuntabel.
\end{abstract}

Keyword: Sistem Pendukung Keputusan, Guru Prestasi, Metode AHP

\begin{abstract}
This decision support system is used to select outstanding teachers and is aimed at SD 095130 Senio Bangun which still uses manual system in assessing the candidates of outstanding teachers. So this system is expected to assist the agency in the process of assessment and determination of outstanding teachers in the area of Pematang Siantar City quickly and accurately. The method used in ranking the selection of teachers achieving achievement in this system using AHP method is a method The workings of this method is almost similar to the workings of the brain, namely by elaborating complex problems into more problems that are more structured and systematic. Where alternatives are used as much 4 teachers with job criteria, education, rank / goals / Space and last sk. The results of ranking in this system are influenced by the selection of preference criteria and determinations entered into the system. The test of this system uses data from 45 teachers, ranking divided according to Kindergarten, SD / MI, SMP / Tsanawiyah, SMA / MA, and SMK. Of the several trials that have been done to determine the achieving teacher, the ranking results are much faster and more accountable.
\end{abstract}

Keyword: Decision Support System, Achievement Teacher, AHP Method

\section{PENDAHULUAN}

Guru adalah pendidik profesional dengan tugas utama mendidik, mengajar, membimbing, mengarahkan, melatih, menilai, dan mengevaluasi peserta didik pada pendidikan anak usia dini jalur pendidikan formal, pendidikan dasar, dan pendidikan menengah. Untuk melaksanakan tugasnya secara profesional, guru tidak hanya dituntut memiliki kemampuan teknis edukatif, tetapi 
juga harus memiliki kepribadian yang kokoh sehingga dapat menjadi sosok panutan bagi, siswa, keluarga, maupun masyarakat. Selaras dengan kebijaksanaan pembangunan yang meletakkan pengembangan sumber daya manusia (SDM) sebagai prioritas pembangunan nasional maka kedudukan dan peran guru semakin strategis untuk mempersiapkan SDM yang berkualitas dalam menghadapi era global [1]. Guru adalah contoh pedoman nomor kedua dari orang tua, dan sebagai pembimbing/orang tua jika berada di sekolah [2], maka dari itu guru haruslah memiliki sikap yang teladan dan moral yang baik bagi muridnya, dan membuat para murid agar dapat tenang,nyaman, berada di sekolah tanpa adanya tekanan dari sekolah maupun orang tua .pada kenyataan yang kita telah melihat banyak kasus yang terjadi di sekolah, sebagai contoh yang diambil adalah kekerasan pada murid di sekolah dasar, pelecehan seksual pada murid sekolah dasar, yang mengakibatkan anak tersebut trauma, dan enggan untuk bersekolah. Sehubungan dengan itu maka diperlukan sebuah sistem pengambil keputusan dengan judul "Menganalisa Metode AHP dalam merekomendasikan guru teladan di SD 095130 Senio Bangun". Agar sekolah dapat mengambil keputusan dengan adanya paper ini, Dalam pemilihan guru teladan dan dalam penerimaan guru yang akan mengajar di sekolah.

Sistem pendukung keputusan adalah bagian dari sistem informasi berbasis komputer yang dipakai untuk mendukung pengambilan keputusan. Metode yang digunakan dengan metode Analytical Hierarchy Process (AHP) [3]. Metode AHP merupakan salah satu metode pengambilan keputusan yang kemukakan oleh Thomas L. Saaty. Cara kerja dari metode ini hampir mirip dengan cara kerja otak, yaitu dengan cara menguraikan masalah kompleks menjadi masalah lebih yang lebih terstruktur dan sistematis. Penguraian permasalahan ini dilakukan dengan menggunakan prinsip hirarki. Menurut Saaty, hirarki tersebut disusun menjadi struktur yang terdiri dari beberapa tingkatan/level. Urutan tingkatan/level tersebut adalah tujuan, kriteria, sub kriteria dan seterusnya hingga sampai tingkat alternatif [4].

Metoda AHP pada dasarnya mampu menyediakan proses analitis secara semiterstruktur yang pada gilirannya mampu digunakan untuk mengkombinasikan penilaian-penilaian dari berbagai alternatif dan kriteria yang ada [5].

Penelitian terdahulu yang berkaitan dengan metode AHP adalah pemilihan siswa berprestasi menggunakan metode analytical hierarchi process (ahp) pada SMK negeri irundeng [6], guru berprestasi menggunakan fuzzy-analytic hierarchy process (f-ahp) [4], penerapan metode ahp(analythic hierarchy process)untuk menentukan kualitas gula tumbu[6],Penerapan Metode Analytical Hierarchy Process (AHP) dalam Menentukan Ras Ayam Serama [8], desain sistem pendukung keputusan penilaian kinerja karyawan Ipk alfabank Semarang dengan metode Analytical hierarchy process (AHP) [9].

\section{METODOLOGI PENELITIAN 2.1 Prosedur Metode AHP}

Pada dasarnya, prosedur atau langkah-langkah dalam metode AHP meliputi (Kusrini, 2007: 135) :

1. Memdefenisikan masalah dan menentukan solusi yang diinginkan, lalu menyusun hierarki daripermasalahan yang dihadapi.Penyusunan hierarki adalah dengan menetapkan tujuan yang merupakan sasaran sistem secara keseluruhan pada level teratas.

2. Menentukan prioritas elemen

a. Langkah pertama dalam menentukan prioritas elemen adalah membuat perbandingan pasangan, yaitu membandingkan elemen secara berpasangan sesuai kriteria yang diberikan.

b. Matriks perbandingan berpasangan diisi menggunakan bilangan untuk merepresentasikan kepentingan relatif dari suatu elemen terhadap elemen yang lainnya.

3. Sintesis Pertimbangan-pertimbangan terhadap perbandingan berpasangan disintesis untuk memperoleh keseluruhan prioritas. Hal-hal yang dilakukan dalam langkah ini adalah:

a. Menjumlahkan nilai-nilai dari setiap kolom pada matriks.

b. Membagi setiap nilai dari kolom dengan total kolom yang bersangkutan untuk memperoleh normalisasi matriks.

c. Menjumlahkan nilai-nilai dari setiap baris dan membaginya dengan jumlah elemen untuk mendapatkan nilai rata-rata.

4. Mengukur konsistensi Dalam pembuatan keputusan, penting untuk mengetahui seberapa baik konsis baik konsistensi yang ada karena kita tidak menginginkan keputusan berdasarkan pertimbangan dengan konsistensi yang rendah. Hal-hal yang dilakukan dalam langkah ini adalah:

a. Kalikan setiap nilai pada kolom pertama dengan prioritas relative elemen pertama, nilai pada kolom kedua dengan prioritas relative elemen kedua, dan seterusnya.

b. Jumlahkan setiap baris.

c. Hasil dari penjumlahan baris dibagi dengan elemen prioritas relatif yang bersangkutan.

d. Jumlahkan hasil bagi di atas dengan banyaknya elemen yang ada, hasilnya disebut $\lambda$ maks.

5. Hitung Consistency Index $(\mathrm{Cl})$ dengan rumus: $\mathrm{Cl}=(\lambda$ maks $-n) / \mathrm{n}$ Di mana $: \mathrm{n}=$ Banyaknya elemen

6. Hitung Rasio Konsistensi/Consistency Rasio (CR) dengan rumus: $\mathrm{CR}=\mathrm{Cl} / \mathrm{RC}$ Di mana : $\mathrm{CR}$ = Consistency Rasio $\mathrm{Cl}=$ Consistency Index IR = Indeks Random Consistency

7. Memeriksa konsistensi hierarki. Jika nilainya lebih dari $10 \%$, maka penilaian dara judgment harus diperbaiki. Namun jika rasio konsistensi (Cl/IR) kurang atau sama dengan 0,1, maka hasil perhitungan bisa dinyatakan benar. Daftar Indeks Random Konsistensi (IR) dapat dilihat dalam tabel berikut [6]:

\section{Tabel 1 RC}

\begin{tabular}{|l|l|l|l|l|}
\hline $\mathbf{N}$ & 1 & 2 & 3 & 4 \\
\hline $\mathbf{R}$ & 0,0 & 0,0 & 0.5 & 0.9 \\
\hline
\end{tabular}

SPK: Analisa Metode AHP Pada Guru Berprestasi di SD 095130 Senio Bangun. 


\begin{tabular}{|l|l|l|l|l|}
\hline $\mathbf{C}$ & 0 & 0 & 8 & 0 \\
\hline
\end{tabular}

Jika $\mathrm{CR}<0.1$ maka nilai perbandingan berpasangan pada matriks kriteria diberikan konsisten. Jika CR $>0.1$, maka nilai perbandingan berpasangan pada matriks kriteria tidak konsisten. Jadi apabila matriks kriteria tersebut tidak konsisten, maka pengisian nilai-nilai pada matrik berpasangan pada unsur kriteria maupun alternatif harus diulang.

\begin{tabular}{|c|c|c|c|c|}
\hline Kriteria & $\begin{array}{c}\text { Jabat } \\
\text { an }\end{array}$ & $\begin{array}{l}\text { Pendidi } \\
\text { kan }\end{array}$ & $\begin{array}{c}\text { Pangkat/ } \\
\text { Gol/Rua } \\
\text { ng }\end{array}$ & $\begin{array}{c}\text { Sk } \\
\text { Terak } \\
\text { hir }\end{array}$ \\
\hline $\begin{array}{c}\text { Nirwana } \\
\text { Purba S,Pdl }\end{array}$ & Baik & $\begin{array}{c}\text { Sangat } \\
\text { Baik }\end{array}$ & Baik & Cukup \\
\hline $\begin{array}{c}\text { Riana } \\
\text { Simorangkir } \\
\text { S,Pd }\end{array}$ & Baaik & Cukup & $\begin{array}{c}\text { Sangat } \\
\text { Baik }\end{array}$ & $\begin{array}{l}\text { Sanga } \\
\text { t Baik }\end{array}$ \\
\hline $\begin{array}{c}\text { Tionelia } \\
\text { Panggabean } \\
\text { S,pd }\end{array}$ & $\begin{array}{l}\text { Sanga } \\
\text { t Baik }\end{array}$ & Baik & $\begin{array}{l}\text { Sangat } \\
\text { Baik }\end{array}$ & Baik \\
\hline $\begin{array}{c}\text { Tri Widyastuty } \\
\text { S,pd }\end{array}$ & $\begin{array}{l}\text { Sanga } \\
\text { t Baik }\end{array}$ & Baik & $\begin{array}{l}\text { Sangat } \\
\text { Baik }\end{array}$ & Cukup \\
\hline
\end{tabular}

Keterangan nilai indikator:

Sangat Buruk $(\mathrm{SBr})=0$

Buruk $(\mathrm{Br})=0.25$

Cukup $(C)=0.50$

Baik $(B)=0.75$

Sangat Baik $(\mathrm{SB})=1$

Tabel 3 Nilai Kuesioner Siswa Berdasarkan Indikator

\begin{tabular}{|c|c|c|c|c|}
\hline Kriteria & $\begin{array}{c}\text { Jab } \\
\text { atan }\end{array}$ & $\begin{array}{c}\text { Pendi } \\
\text { dikan }\end{array}$ & $\begin{array}{c}\text { Pangkat/G } \\
\text { ol/Ruang }\end{array}$ & $\begin{array}{c}\text { Sk } \\
\text { Terak } \\
\text { hir }\end{array}$ \\
\hline $\begin{array}{c}\text { Nirwana Purba } \\
\text { S,Pdl }\end{array}$ & 0.75 & 1 & 0.75 & 0.50 \\
\hline $\begin{array}{c}\text { Riana } \\
\text { Simorangkir } \\
\text { S,Pd }\end{array}$ & 0.75 & 0.50 & 1 & 1 \\
\hline $\begin{array}{c}\text { Tionelia } \\
\text { Panggabean } \\
\text { S,pd }\end{array}$ & 1 & 0.75 & 1 & 0.75 \\
\hline $\begin{array}{c}\text { Tri Widyastuty } \\
\text { S,pd }\end{array}$ & 1 & 0.75 & 1 & 0.50 \\
\hline
\end{tabular}

Table 4 Tabel Nilai Kepentingan

\begin{tabular}{|l|l|}
\hline Nilai & \multicolumn{1}{c|}{ Keterangan } \\
\hline 1 & Kedua elemen sama penting \\
\hline 3 & Elemen A sedikit lebih penting dari elemen B \\
\hline 5 & Elemen A lebih penting dari elemen B \\
\hline 7 & Elemen A jelas lebih penting dari elemen B \\
\hline 9 & Elemen A mutlak lebih penting dari elemen B \\
\hline $2,4,6,8$ & $\begin{array}{l}\text { Nilai-nilai antara dua Pertimbangan yang } \\
\text { berdekatan }\end{array}$ \\
\hline
\end{tabular}

Tabel 5 Tabel Kriteria

\begin{tabular}{|l|l|}
\hline No & \multicolumn{1}{|c|}{ Kriteria penilaian } \\
\hline 1 & Jabatan $(\mathrm{J})$ \\
\hline 2 & Pendidikan (Pend) \\
\hline 3 & Pangkat/Gol/Ruang (PGR) \\
\hline 4 & Sk Terakhir (ST) \\
\hline
\end{tabular}

Tabel 6 Tabel Guru Berprestasi

\begin{tabular}{|l|c|}
\hline No & Nama Guru \\
\hline
\end{tabular}

SPK: Analisa Metode AHP Pada Guru Berprestasi di SD 095130 Senio Bangun
Tabel 8 Bentuk Matriks Berpasangan 5 Jenis Kriteria Dalam pemilihan guru berprestasi

\begin{tabular}{|c|c|c|c|c|}
\hline & $\begin{array}{c}\text { Nirwana } \\
\text { Purba S,Pdl }\end{array}$ & $\begin{array}{c}\text { Riana } \\
\text { Simorangkir S,Pd }\end{array}$ & $\begin{array}{c}\text { Tionelia } \\
\text { Panggabean S,pd }\end{array}$ & $\begin{array}{c}\text { Tri Widyastuly } \\
\text { S,pd }\end{array}$ \\
\hline Nirwana Purba S,Pdl & 1 & 3 & 7 & 6 \\
\hline Riana Simorangkir S,Pd & $1 / 3$ & 1 & 3 & 7 \\
\hline Tionelia Panggabean S,pd & $1 / 7$ & $1 / 3$ & 1 & 3 \\
\hline Tri Widyastuty S,pd & $1 / 6$ & $1 / 7$ & $1 / 3$ & 1 \\
\hline
\end{tabular}

Tabel 9 Masukan dan Hasil Perhitungan Alternatif

Untuk menghitung tabel 9 adalah dengan cara: Menjumlahkan setiap kolom

\begin{tabular}{|c|c|c|c|c|}
\hline Nirwana & $\begin{array}{c}\text { Riana } \\
\text { Purba } \\
\text { S,Pdl }\end{array}$ & $\begin{array}{c}\text { Simorangk } \\
\text { ir S,Pd }\end{array}$ & $\begin{array}{c}\text { Tionelia } \\
\text { Panggabea } \\
\text { n S,pd }\end{array}$ & $\begin{array}{c}\text { Tri } \\
\text { Widyast } \\
\text { uty S,pd }\end{array}$ \\
\hline $\begin{array}{c}\text { Nirwana } \\
\text { Purba } \\
\text { S,Pdl }\end{array}$ & 1 & 3 & 7 & 6 \\
\hline $\begin{array}{c}\text { Riana } \\
\text { Simorangki } \\
\text { r S,Pd }\end{array}$ & 0.33 & 1 & 3 & 7 \\
\hline $\begin{array}{c}\text { Tionelia } \\
\text { Panggabea } \\
\text { n S,pd }\end{array}$ & 0.14 & 0.33 & 1 & 3 \\
\hline $\begin{array}{c}\text { Tri } \\
\text { Widyastuty } \\
\text { S,pd }\end{array}$ & 0.16 & 0.14 & 0.33 & 1 \\
\hline jumlah & $\mathbf{1 . 6 3}$ & $\mathbf{4 . 4 7}$ & $\mathbf{1 1 . 3 3}$ & 17 \\
\hline
\end{tabular}

Tabel 10 Masukan dan Hasil Perhitungan Kriteria

Untuk menghitung tabel 10 adalah dengan cara:

Membagikan setiap kolom dengan hasil total kolom

\begin{tabular}{|c|c|c|c|c|}
\hline & J & Pend & PGR & ST \\
\hline J & 1 & 3 & 5 & 7 \\
\hline Pend & 0.33 & 1 & 3 & 5 \\
\hline PGR & 0.2 & 0.33 & 1 & 3 \\
\hline ST & 0.14 & 0.2 & 0.33 & 1 \\
C & 1.67 & 4.53 & 9.33 & 16 \\
\hline
\end{tabular}

Tabel 11 Hasil Pembagian jumlah kolom kriteria Setelah hasil pembagian setiap kolom maka setiap baris dijumlah

\begin{tabular}{|c|c|c|c|c|c|c|}
\hline & J & Pend & PGR & ST & Jumlah & $\begin{array}{c}\text { Rata- } \\
\text { Rata }\end{array}$ \\
\hline J & 0.59 & 0.66 & 0.53 & 0.43 & $\mathbf{2 . 2 1}$ & $\mathbf{0 . 5 5}$ \\
\hline Pend & 0.19 & 0.22 & 0.32 & 0.31 & $\mathbf{1 . 0 4}$ & $\mathbf{0 . 2 6}$ \\
\hline PGR & 0.11 & 0.07 & 0.10 & 0.18 & $\mathbf{0 . 4 6}$ & $\mathbf{0 . 1 1}$ \\
\hline ST & 0.08 & 0.04 & 0.03 & 0.06 & $\mathbf{0 . 2 1}$ & $\mathbf{0 . 0 5}$ \\
\hline
\end{tabular}

Tabel 12 Hasil pembagian jumlah kolom Alternatif 


\begin{tabular}{|c|c|c|c|c|c|}
\hline & $\begin{array}{l}\text { Niwana } \\
\text { Putaa } \$, \text { pul } \\
\end{array}$ & $\begin{array}{c}\text { Riana } \\
\text { Simorangki S,Pd }\end{array}$ & $\begin{array}{c}\text { Tionelia } \\
\text { Pangabean S.pd }\end{array}$ & $\begin{array}{c}\text { TriWdyastly } \\
\text { S,pd }\end{array}$ & Jumlah \\
\hline Niwana Pubba S,Pol & 0.61 & 0.67 & 0.61 & 0.35 & 2.24 \\
\hline Riara Simorangkir S,Pd & 0.20 & 0.22 & 0.26 & 0.41 & 1.09 \\
\hline Torelia Parggadean S,pd & 0.08 & 0.07 & 0.08 & 0.17 & 0.4 \\
\hline TriWdyastuty S.pd & 0.09 & 0.03 & 0.02 & 0.05 & 19 \\
\hline
\end{tabular}

Dalam pembuatan keputusan, penting untuk mengetahui seberapa baik konsistensi yang ada karena kita tidak menginginkan keputusan berdasarkan pertimbangan dengan konsistensi yang rendah.Pengukuran konsistensi dikerjakan sebanyak jumlah matrik perbandingan yang ada, dalam kasus ini pengukuran konsistensi di lakukan sebanyak empat kali.Pengukuran yang pertama dilakukan untuk kriteria utama, dengan bentuk perhitungansebagai berikut:

a. Mengalikan setiap nilai pada kolom pertama dengan prioritas relatif elemen pertama, kemudian jumlahkan setiap barisnya.

$$
\begin{aligned}
& =\left(\begin{array}{llll}
1 & 3 & 5 & 7 \\
0.33 & 1 & 3 & 5 \\
0.2 & 0.33 & 1 & 3 \\
0.14 & 0.2 & 0.33 & 1
\end{array}\right) \times\left(\begin{array}{l}
0.55 \\
0.26 \\
0.11 \\
0.05
\end{array}\right) \\
& =\left(\begin{array}{cccc}
0.55 & 0.78 & 0.55 & 0.35 \\
0.18 & 0.26 & 0.33 & 0.25 \\
0.11 & 0.08 & 0.11 & 0.15 \\
0.07 & 0.05 & 0.03 & 0.05
\end{array}\right) \\
& =\left(\begin{array}{c}
2.23 \\
1.02 \\
0.45 \\
0.2
\end{array}\right)
\end{aligned}
$$

b. Hasil dari penjumlahan baris dibagi dengan elemen prioritas relatif yang bersangkutan.

$$
\left(\begin{array}{c}
2.23 \\
1.02 \\
0.45 \\
0.2
\end{array}\right):\left(\begin{array}{c}
0.55 \\
0.26 \\
0.11 \\
0.05
\end{array}\right)=\left(\begin{array}{c}
4.05 \\
3.92 \\
4.09 \\
4
\end{array}\right)
$$

c. Jumlahkan hasil bagi di atas dengan banyaknya elemen yang ada, hasilnya disebut imaksimal.

$\lambda \max =(4.05+3.92+4.09+4) / 4=4.015$

d. Hitung Consistency Index $(\mathrm{Cl})$.

$\mathrm{Cl}=(\lambda \max -\mathrm{n}) /(\mathrm{n}-1)$

$(4.015-4) /(4-1)=0,005$

e. Hitung Consistency Ratio (CR), untuk $n=3$ maka

$\mathrm{RI}=0,58$ (lihat tabel Random Consistency,

Saaty).

$\mathrm{CR}=\mathrm{Cl} / \mathrm{RC} \rightarrow 0,005 / 0,9=0,005$

Karena $\mathrm{CR}<10 \%$ maka perhitungan ini dinyatakan benar.

\begin{tabular}{|c|}
\hline Bobot \\
\hline 0.55 \\
\hline 0.26 \\
\hline 0.11 \\
\hline 0.05 \\
\hline$\sum_{j=1} W j^{i} r i j$ \\
\hline
\end{tabular}

$\mathrm{V} 1=(1 \times 0.55)+(0.33 \times 0.26)+(0.2 \times 0.11)+(0.14 \mathrm{x}$ $0.05)=5.114$

$V 2=(3 \times 0.55)+(1 \times 0.26)+(0.33 \times 0.11)+(0.2 x$

$0.05)=1.95$

$V 3=(5 \times 0.55)+(3 \times 0.26)+(1 \times 0.11)+(0.33 x$

$0.05)=3.65$

$V 4=(7 \times 0.55)+(5 \times 0.26)+(3 \times 0.11)+(1 \times 0.05)=5.53$

\begin{tabular}{|c|c|}
\hline Nirwana Purba S,Pdl & 5.11 \\
\hline Riana Simorangkir S,Pd & 1.95 \\
\hline Tionelia Panggabean S,pd & 3.65 \\
\hline Tri Widyastuty S,pd & $\mathbf{5 . 5 3}$ \\
\hline
\end{tabular}

Maka dapat disimpulkan bahwa Tri Widyastuty s,Pd adalah guru berprestasi menurut kriteria yang ada

\section{KESIMPULAN}

Berdasarkan uraian pembahasan dari penelitian yang telah dilakukan, maka dapat diperolah kesimpilan sebagai berikut :

1. Sistem pendukung keputusan yang sudah ada dapat mempermudah panitia dalam penentuan siswa berprestasi untuk mempercepat proses pemilihan Guru dengan cara menginput nilainilai dan langsung mendapatkan hasilnya, dibandingkan dengan sebelumnya berprestasi masih dengan cara manual dengan cara memberi pilihan pada Guru berprestasi.

2. Perancangan metode AHP untuk penentuan Guru berprestasi bagi guru-guru dapat di terapkan dengan sangat baik dalam pengimplementasinya, AHP mampu menunjukkan bahwa satu alternatif merupakan prioritas keputusan

\section{UCAPAN TERIMAKASIH.}

Ucapan terimakasih kepada STIKOM TUNAS BANGSA Pematang Siantar, Dosen Pembimbing, SDN 095130 Senio Bangun dan semua orang yang mengambil bagian dalam penelitian ini.

\section{DAFTAR PUSTAKA}

[1] M. I. Irawan, K. Hulu, S. Selatan, K. Selatan, and T. L. Saaty, "Pemilihan Guru Berprestasi," vol. 2, no. 1, pp. 63-68, 2011.

[2] Tonni Limbong, Efendi Napitupulu, Sriadhi and Pandi Barita Nauli Simangunsong, "Learning Application Soft Skill for Facial with Computer Assisted Instruction Model", International Journal of Scientific Research in Science, Engineering and Technology, Print ISSN: 2395-1990, Online ISSN : 2394-4099 Vol. 4 Issue.1, pp, 561-570, 2018.

[3] I. Bahasa, P. Php, and D. A. N. Mysql, "VOL . 10 NO . 1 April 2017 VOL . 10 NO . 1 April 2017," vol. 10, no. 1, pp. 72-83, 2017.

[4] D. R. Bahari, E. Santoso, and S. Adinugroho, "Sistem Pendukung Keputusan Penentuan Guru Berprestasi Menggunakan FuzzyAnalytic Hierarchy Process ( F-AHP ) ( Studi Kasus: SMA Brawijaya Smart School )," J. Pengemb. Teknol. Inf. dan Ilmu Komput., vol. 2, no. 5, pp. 2095-2101, 2018.

[5] A. Nugroho and S. Hartati, "Sistem Pendukung Keputusan Berbasis Ahp (Analytical Hierarchy Process) Untuk Penentuan Kesesuaian Penggunaan Lahan (Studi Kasus: Kabupaten Semarang)," Sist. Pendukung Keputusan Berbas. Ahp (Analytical Hierarchy Process. Untuk Penentuan Kesesuaian Pengguna. Lahan 
(Studi, vol. 9, no. 2, pp. 1-14, 2012.

[6] M. O. Ardiansyah and K. Siregar, "Siswa

Berprestasi Menggunakan Metode Analytical," pp. 12-18, 2016.

[7] N. S. Eko Darmanto, Noor Latifah, "Penerapan Metode Ahp ( Analythic Hierarchy Process ) Untuk Menentukan Kualitas Gula Tumbu," J. SIMETRIS, vol. 5, no. 1, pp. 7582, 2014.

[8] W. Fahrozi, "Penerapan Metode Analytical Hierarchy Process (AHP) dalam Menentukan Ras Ayam Serama," Creat. Inf. Technol. J., vol. 3, no. 3, pp. 214-277, 2016.

[9] I. Nomor et al., "Karyawan Lpk Alfabank Semarang Dengan Metode Analytical Hierarchy Process ( AHP )," 2016.

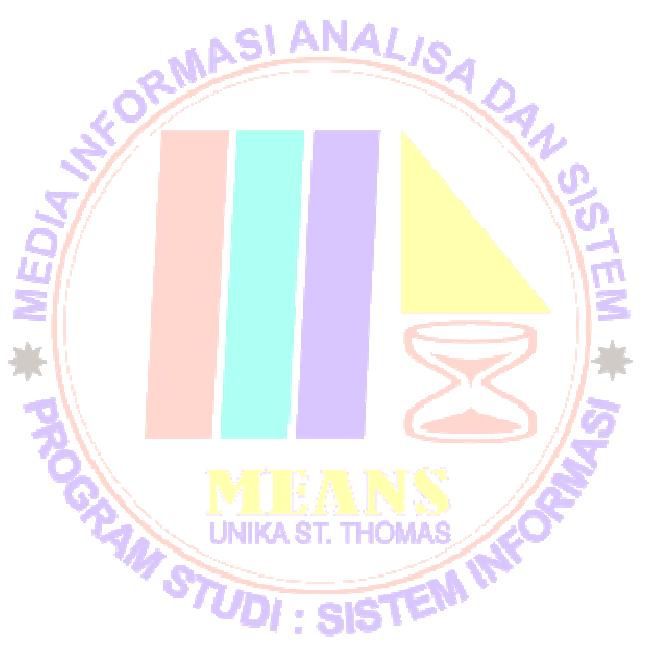

